Tourism in Analysis

DOI: http://dx.doi.org/10.11606/issn.1984-4867.v27i3p500-523

\title{
Baixada Santista ou Costa da Mata Atlântica? Eis a questão: identificação da percepção do visitante sobre a marca Costa da Mata Atlântica
}

\author{
Baixada Santista or Costa da Mata Atlântica? That is the question: visitor's \\ perception of identification on the Costa da Mata Atlantica brand
}

¿Baixada Santista o Costa da Mata Atlântica? Identificando la percepción del visitante sobre la marca Costa da Mata Atlântica

\author{
Cinthia Rolim de Albuquerque Meneguel ${ }^{1}$ \\ Gabriela Toaiari Rodrigues Farinha Cordeiro ${ }^{2}$ \\ Paola Silva de Deus ${ }^{3}$
}

\begin{abstract}
Resumo
A Região Metropolitana da Baixada Santista é composta de nove cidades e, como estratégia de marketing, o selo turístico Costa da Mata Atlântica foi criado para identificar mais facilmente a região. A pesquisa, de caráter descritivo e exploratório, teve como objetivo geral identificar o conhecimento do visitante frente à marca Costa da Mata Atlântica, assim como em relação à terminologia usual "Baixada Santista". Por meio da aplicação de 130 questionários semiestruturados e baseando-se na fundamentação teórica sobre notoriedade de uma marca, identificou-se como resultado que o termo "Baixada Santista" é mais reconhecido entre os visitantes do que a marca Costa da Mata Atlântica. Portanto, ações relacionadas à estratégia de marketing e competitividade turística precisam ser revistas. O estudo objetiva que seus resultados contribuam efetivamente com todos os stakeholders envolvidos com o turismo, possibilitando ações para o reposicionamento da marca turística.
\end{abstract}

Palavras-chave: Baixada Santista; Costa da Mata Atlântica; Marca; Turismo; Notoriedade.

\footnotetext{
1 Doutoranda em Turismo e Hotelaria pela Universidade do Vale do Itajaí (Univali). Mestre em Análise Geoambiental pela Universidade Guarulhos (UnG). Especialização em Formação de Professores com ênfase no Ensino Superior pelo Instituto Federal de São Paulo (IFSP). Docente no curso superior de Gestão de Turismo do pelo Instituto Federal de São Paulo - Campus Cubatão (IFSP). Balneário Camboriu, Santa Catarina, Brasil. E-mail: cameneguel@gmail.com.

2 Graduanda em Tecnologia em Gestão de Turismo pelo Instituto Federal de Educação, Ciência e Tecnologia de São Paulo - Campus Cubatão (IFSP). Cubatão, São Paulo, Brasil. E-mail: gabriela.toaiari@gmail.com.

3 Graduada em Tecnologia em Gestão de Turismo pelo Instituto Federal de Educação, Ciência e Tecnologia de São Paulo - Campus Cubatão (IFSP) Cubatão, São Paulo, Brasil. E-mail: paolasdeus@gmail.com
} 
Tourism in Analysis

\begin{abstract}
Baixada Santista is composed by nine cities and, as a marketing strategy, a tourist brandCosta da Mata Atlântica - had been created to more easily identify the region. The descriptive and exploratory research aimed to identify the visitor's knowledge about Costa da Mata Atlântica brand, as well its relation to the usual terminology "Baixada Santista". Through the application of 130 semi-structured questionnaires, and based on the theoretical framework of the brand's reputation, the identified result was that the term "Baixada Santista" is more recognizable among the visitors than the brand Costa da Mata Atlantica. Therefore, actions related to marketing and tourism competitiveness strategies must be reviewed. The study aims that the results can effectively contribute to all stakeholders involved in tourism, enabling actions to the repositioning of the tourist brand.
\end{abstract}

Keywords: Baixada Santista; Costa da Mata Atlântica; Brand; Tourism; Notoriety.

\title{
Resumen
}

La Baixada Santista está compuesta de nueve ciudades brasileñas, y como estrategia de marketing ha creado un sello turístico para identificar más fácilmente la región, por lo tanto, la marca Costa da Mata Atlântica. Este estudio de carácter descriptivo y exploratorio tuvo como objetivo identificar el conocimiento del visitante acerca de esta marca, así como del término usual "Baixada Santista". A través de la aplicación de 130 cuestionarios semiestructurados y con base en el marco teórico de notoriedad de una marca, se identificó en el resultado que el término "Baixada Santista" es el más reconocido entre los visitantes que la marca Costa da Mata Atlântica. Por lo tanto, las acciones relacionadas con la estrategia de competitividad y comercialización del turismo deben ser revisadas. Los resultados del estudio pueden contribuir eficazmente con todos los actores involucrados en el turismo, lo que permite acciones de reposicionamiento de la marca turística.

Palabras clave: Baixada Santista; Mata da Costa Atlântica; Marca; Turismo; Notoriedad.

\section{Introdução}

Recentemente a gestão do destino e a marca do destino são consideradas importantes para a atribuição de valores dos produtos e dos lugares turísticos. Cada vez mais destinos consolidados vêm trabalhando sua imagem como vantagem competitiva e criando suas marcas a fim de se tornarem únicos.

O tema marca consta na literatura de marketing há mais de 70 anos (BANKS, 1950; GARDNER; LEVY, 1955), contudo, a marca associada ao destino turístico só começa a ser discutida posteriormente com Pritchard e Morgan (1998). 
Tourism in Analysis

Tal tópico atrai o interesse acadêmico, o que é evidenciado na revisão da literatura realizada por Pike (2009), na qual é demonstrado que, entre os anos de 1998 e 2007, houve 74 publicações sobre o tema, realizadas por 102 autores.

Reconhecendo que os destinos podem oferecer características e benefícios semelhantes, Keller (2003) exemplifica que a marca, ou selo turístico, é considerada benéfica tanto para a demanda - pois auxilia o consumidor na tomada de decisão, reduzindo o risco de compra -, assim como para a oferta - já que cria e fornece expectativas de forma diferenciada, favorece a competitividade, entre outras ações.

Para a região turística formada pelos municípios de Bertioga, Cubatão, Guarujá, Santos, São Vicente, Praia Grande, Mongaguá, Itanhaém e Peruíbe - nove cidades pertencentes ao litoral sul paulista - o Santos e Região Convention \& Visitors Bureau (SRC\&VB) criou a marca Costa da Mata Atlântica - em substituição ao emprego popular do termo "Baixada Santista" para a região. Assim, a pergunta da pesquisa indaga: "A marca da Costa da Mata Atlântica tornou-se mais conhecida do que o emprego popular de 'Baixada Santista' entre os visitantes que passam pela região?"

Dessa forma, o presente trabalho teve como objetivo principal identificar o conhecimento do visitante frente a marca Costa da Mata Atlântica e a terminologia usual "Baixada Santista" por meio da teoria da notoriedade. Assim, a pesquisa visou fornecer dados que traduzam a abrangência da marca e que fundamentem tomadas de decisão na divulgação e no seu uso. A partir dessa compreensão, foram determinados os seguintes objetivos secundários para o estudo: entender o conceito de marca; o processo de criação de uma marca; identificar o processo de criação da marca Costa da Mata Atlântica e sua aplicabilidade; identificar, por meio dos visitantes da região, o posicionamento da marca fazendo uso da medida de notoriedade; e, frente aos dados, contribuir para o fortalecimento da região como destino turístico.

Adotou-se para o trabalho a pesquisa descritiva e exploratória, que buscou, com uso da quantificação dos dados, gerar uma análise crítica reflexiva sobre a questão principal da pesquisa. A investigação baseou-se nos resultados da aplicação de 130 questionários, que possibilitaram identificar, entender e compreender o posicionamento da notoriedade da marca Costa da Mata Atlântica. 
Tourism in Analysis

\section{Conceito de marca}

Pesquisas e estudos sobre marca são cada vez mais frequentes no campo das ciências econômicas, já que a marca é um elo de grande importância na relação entre corporações e consumidores - além de integrar os ativos intangíveis das empresas -, e vem gerando alto índice de valor e lucro.

Para Lindon et al. (2004) um produto é algo produzido numa fábrica; uma marca é qualquer coisa que é comprada pelo consumidor; sendo que um produto pode ser copiado por um concorrente ou pode até desaparecer (perder o seu valor), porém uma marca é única, podendo-se dizer que é eterna.

Em um mundo globalizado, os ativos tangíveis são logo replicados e ultrapassados frente ao progresso tecnológico. Por outro lado, os ativos intangíveis são mais difíceis de serem reproduzidos em curto prazo, por necessitarem de maior tempo na sua consolidação. São considerados ativos tangíveis os bens materiais que as empresas possuem, ou seja, o estoque, os veículos, as máquinas, as construções. Já ativos intangíveis são os bens invisíveis num primeiro momento, mas que se tornam diferenciais da empresa, tais como capacidade de criação dos colaboradores, conhecimento coletivo, processos utilizados na empresa (patentes) e marca desenvolvida para representar a empresa.

Uma marca é um nome diferenciado e/ou símbolo (tal como um logotipo, marca registrada, ou desenho de embalagem) destinado a identificar os bens ou serviços de um vendedor ou de um grupo de vendedores e a diferenciar esses bens e serviços daqueles dos concorrentes. Assim, uma marca sinaliza ao consumidor a origem do produto e protege, tanto o consumidor quanto o fabricante, dos concorrentes que oferecem produtos que pareçam idênticos. (AAKER 1998, p. 7)

A sinalização da origem do produto ou serviço representa uma segurança ao consumidor, a certeza de comprar algo de qualidade reconhecida. Aaker (1998) também cita a proteção que a marca gera, ou seja, os direitos garantidos por lei ao proprietário da marca.

Kotler (1991, p. 404) define marca como "um nome, termo, sinal, símbolo, ou design, ou a combinação destes elementos que visam identificar produtos ou serviços de uma empresa ou grupo e que a diferencia dos seus competidores". Assim, a marca é formada pela junção entre os elementos visíveis - cores, símbolos, palavras, tipo de fonte utilizada. Como as 
características de um produto podem ser facilmente copiadas, as marcas surgem como uma das melhores ferramentas para criar diferenciação entre produtos (KOTLER; GERTNER, 2002). Compreende-se que a principal função da marca é a diferenciação na mente do consumidor entre uma opção e outra; é uma potente ferramenta empresarial para conquistar a preferência do público e fixar a marca em sua mente. A marca também acaba por gerar um contrato invisível com o consumidor, atendendo ou superando suas expectativas e atuando como proteção tanto para o produtor quanto para o consumidor.

De acordo com Pimentel, Pinho e Vieira (2006) as marcas têm outras funções: concorrencial, identificadora, de individualização, de revelação, de diferenciação, publicitária e de diferenciação no âmbito da própria empresa; e, ao comprar o bem, o consumidor descobre o produto que a marca assinala.

A função de diferenciação diz respeito ao fato de uma marca, ou produto, tornar-se diferenciado na sua categoria; a função publicitária está relacionada à divulgação e à promoção da marca do produto junto ao consumidor, que deixa de ser uma mercadoria anônima e sem valor agregado; a função de diferenciação interna são diferenciações de um mesmo produto para agradar diversos níveis sociais de públicos, como funções extras em equipamentos, por exemplo.

Independente da função da marca, o mais importante é a estratégia que será utilizada para tornar e manter essa marca entre as marcas de sucesso. Para essa estratégia, alguns autores utilizam a denominação branding, enquanto outros utilizam o termo gestão de marcas.

As marcas também acrescentam atributos funcionais (tangíveis) de um produto ou serviço; e atributos emocionais (intangíveis), psicológicos e sociológicos (KAPFERER, 2000; MOILANEN; RAINISTO, 2009).

Também cabe citar que a marca é um fator relevante de status social. Marcas de vestuário, perfume e automóveis, por exemplo, tornam-se referências à qual classe social o indivíduo pertence e ostenta. O consumo de determinadas marcas também é estudado pela neurociência, para descobrir os efeitos que ela causa na mente das pessoas - este artigo não explora essa questão, porém existem pesquisas que abordam essas vertentes do estudo de marcas.

Simões e Dibb (2001, p. 222) excedem o pensamento de que a marca é somente uma figura e atribuem à marca "a missão, os valores, crenças, comunicação, cultura e a totalidade do design" adotados pela corporação. Por esse motivo, há dificuldade de se construir uma marca notável, pois esta detém "um elevado grau de intangibilidade, complexidade e 
Tourism in Analysis

responsabilidade social”. Entende-se que, assim como a instituição, a marca é um organismo vivo, dinâmico, que necessita de contínuos ajustes para se manter na predileção do público - exposto a muitas informações diariamente.

Ao que se refere ao destino:

Marca Destino é o conjunto de atividades de marketing (1) que suporta a criação de um nome, símbolo, logotipo, palavra marca ou outro gráfico que prontamente identifica e diferencia um destino; (2) consistentemente para transmitir a expectativa de uma viagem de experiência inesquecível; (3) serve para consolidar e reforçar a ligação emocional entre o visitante e o destino; e (4) reduz os custos de pesquisa do consumidor e risco percebido. Coletivamente, essas atividades servem para criar uma imagem de destino que influencia positivamente na escolha do consumidor. (BLAIN; LEVY; RITCHIE, 2005, p. 337)

Assim, as marcas turísticas influenciam no crescimento dos diversos ramos da economia por gerarem diferenciação e valor. Para Kapferer (2004, p. 13) marca é uma "ideia partilhada, desejável e exclusiva, embebida nos produtos, serviços, lugares e experiências".

No turismo, cada destino é diferente do outro, e uma das formas de demonstrar essa exclusividade é por meio da marca, um símbolo para ficar na lembrança do turista e criar relações entre o local, aos produtos exclusivos da região, aos costumes locais e às experiências vividas.

\section{Processo de criação de uma marca}

Quando se visualiza uma marca, não é imaginado como os seus criadores chegaram naquele resultado, ou então, não se sabe o porquê daquele símbolo representar um produto, uma empresa ou então um destino turístico.

A construção de uma marca forte requer um cuidadoso planejamento e gigantescos investimentos no longo do prazo. Na essência de uma marca bem-sucedida existe um excelente produto ou serviço, sustentado por um marketing desenvolvido e executado com criatividade. (KOTLER; KELLER, 2000, p. 268)

Para que esse planejamento dê certo, alguns critérios de escolha do elemento da marca devem ser obedecidos. Desse modo, a facilidade de memorização; transmissão de significado; que ela seja desejável e transferível; de fácil adaptação; e protegida juridicamente. 
Tourism in Analysis

Partindo desse pressuposto, alguns itens não podem deixar de ser levados em consideração no processo da criação de uma marca. O nome, as cores, o desenho (design), a proteção legal e outros fatores são elementos indispensáveis para a constituição e a legitimidade de uma marca. No que se refere ao nome, Martins (2005, p. 29) relata que "criar nomes, portanto, requer atenção redobrada, principalmente se o seu objetivo for estabelecer marcas de sucesso", pois o nome deve ser curto - de fácil memorização -, simples e de fácil pronúncia - sem seguir tendências, já que a intenção é que ele nunca fique ultrapassado.

Para o desenho da marca, deve-se utilizar cores que agucem a imaginação, para que aquilo que se deseja passar por meio da imagem da marca seja absorvido por aquele que a contempla. "A escolha da cor é uma providência importante. Mais do que a palavra, a cor adequada diz muito sobre a imagem da marca ou mesmo das impressões que se deseja refletir no mercado" (MARTINS, 2005, p. 41).

No Brasil, em 1970, criou-se uma autarquia federal, ligada ao Ministério do Desenvolvimento, Indústria e Comércio Exterior, o Instituto Nacional da Propriedade Industrial (INPI), que tem como responsabilidade melhorar, difundir e administrar o processo brasileiro de permissão e direitos de propriedade intelectual para a indústria.

Os serviços atribuídos ao INPI são: registro de marcas; concessão de patentes; registro de desenhos industriais; registro de programa de computador, por meio do código-fonte e do código-objeto; indicação geográfica de produtos ou serviços; transferência de tecnologia, entre outros.

Assim, toda marca deve ser registrada no INPI, para que, dessa forma, os direitos sobre ela não sejam perdidos, ou então, tomados por terceiros.

A regulação das marcas registradas é realizada pela Lei da Propriedade Industrial $n^{\circ}$ 9.279, de 1996, que em seu artigo 123 registra marca de produto ou serviço, marca de certificação e marca coletiva.

Para este estudo, cabe ressaltar que, de acordo com levantamento realizado pelo INPI no ano 2014, cerca de 157.016 marcas foram depositadas para registro. Dentre elas, 127.925 têm o depositante como residente do Brasil, sendo que 874 são residentes da Região Metropolitana da Baixada Santista. Dos depositantes residentes do Brasil, apenas 85.810 foram registradas, entre elas o selo turístico Costa da Mata Atlântica. 
Tourism in Analysis

\section{Breve contextualização da "Baixada Santista" e da Costa da Mata Atlântica}

\subsection{A "Baixada Santista"}

"Baixada Santista" é o nome popular dado à Região Metropolitana da Baixada Santista RMBS -, região criada em 1996 pela Lei complementar estadual nº 815, de 30 de julho de 1996. Localizada à 59 quilômetros da capital paulista, a região é composta pelos municípios de Bertioga, Cubatão, Guarujá, Itanhaém, Mongaguá, Peruíbe, Praia Grande, Santos e São Vicente. De acordo com o Instituto Brasileiro de Geografia e Estatística (2012), a região possui uma área aproximada de $2.420,50$ quilômetros quadrados - o que equivale a menos de $1 \%$ do território do estado de São Paulo -, e população de 1.749.343 - o que corresponde a mais de 4\% da população total do estado -, o que resulta em uma densidade demográfica quatro vezes maior do que a do estado de São Paulo. Com um produto interno bruto (PIB) de 60.076,05 milhões de reais (INSTITUTO BRASILEIRO DE GEOGRAFIA E ESTATÍSTICA, 2012) a região compõe mais de $4 \%$ do $\mathrm{PIB}$ estadual.

A RMBS é constituída de 65 quilômetros de extensão litorânea banhada pelo Oceano Atlântico e, no seu extremo oposto, é delimitada pela Serra do Mar. A localidade possui rodovias, dois aeroportos e o maior porto da América Latina - o complexo portuário de Santos -, o qual influencia no comércio exterior brasileiro e também no de países do Mercosul, além de contar com um terminal marítimo de passageiros, no qual são recebidos cruzeiros marítimos de inúmeras partes do mundo.

Quadro 1 - Características das cidades da RMBS

\begin{tabular}{|l|c|c|c|c|}
\hline Cidade & $\begin{array}{c}\text { População } \\
\mathbf{2 0 1 5}\end{array}$ & $\begin{array}{c}\text { Área (em km } \\
\mathbf{2 0 1 5}\end{array}$ & $\begin{array}{c}\text { Participação dos } \\
\text { serviços no total do } \\
\text { valor adicionado } \\
\text { (em \%) / 2012 }\end{array}$ & $\begin{array}{c}\text { IDHM } \\
\mathbf{2 0 1 0}\end{array}$ \\
\hline Santos & 423.579 & 280,67 & 76,47 & 0,84 \\
\hline São Vicente & 345.231 & 147,89 & 85,98 & 0,768 \\
\hline Guarujá & 303.376 & 143,58 & 78,57 & 0,751 \\
\hline Praia Grande & 290.918 & 147,07 & 85,86 & 0,754 \\
\hline Cubatão & 124.043 & 142,88 & 41,88 & 0,737 \\
\hline Itanhaém & 92.956 & 601,85 & 83,08 & 0,745 \\
\hline Peruíbe & 62.977 & 324,55 & 84,21 & 0,749 \\
\hline Bertioga & 55.660 & 490,15 & 85,82 & 0,73 \\
\hline Mongaguán & 50.603 & 141,87 & 82,93 & 0,754 \\
\hline Total & 1.749 .343 & $2.420,50$ & \multicolumn{2}{|l}{} \\
\cline { 1 - 3 } & &
\end{tabular}

Fonte: Elaboração dos autores. Fonte de Dados: AGEM. 2015. 
O município de Cubatão é a única cidade não litorânea da RMBS e também a única da região que não é considerada estância ${ }^{4}$. A cidade, que na década de 1980, foi considerada a mais poluída do mundo pela Organização das Nações Unidas, no ano de 1992 recebeu, da mesma organização, o título de cidade-símbolo da recuperação ambiental, graças aos esforços conjuntos da comunidade, do governo e das indústrias. Sua principal fonte de renda é oriunda do polo industrial, o qual, segundo o Centro das Indústrias do Estado de São Paulo (CENTRO DAS INDÚSTRIAS DO ESTADO DE SÃO PAULO, 2015), é considerado o maior polo químico e petroquímico da América Latina em harmonia com o meio ambiente.

A cidade de Santos é a sede da RMBS, a mais populosa da região e a que abriga o Porto de Santos. O município oferece infraestrutura diversificada para atender moradores, empresas e visitantes. É o único município da região que possui IDHM (Índice de Desenvolvimento Humano Municipal) considerado "muito alto" pelo PNUD - Programa das Nações Unidas para o Desenvolvimento -, sendo o $3^{\circ}$ melhor do estado. Tal fator contribuiu para que, em 2014, Santos liderasse o ranking "Melhores e maiores cidades brasileiras"(ATLAS DO DESENVOLVIMENTO HUMANO NO BRASIL, 2013). As demais cidades - Guarujá, Bertioga, Itanhaém, Mongaguá, Peruíbe, Praia Grande e São Vicente - têm como principal fonte de renda o comércio e a prestação de serviços, incluindo o turismo.

Apesar de todas as qualidades dos municípios da RMBS, a região também possui inúmeros problemas inerentes a grandes regiões, tais como: excesso de veículos, que causam lentidão no trânsito; poluição ambiental causada, principalmente, pelo porto e pelas indústrias; crescentes casos de roubos e violência, que afastam turistas; e falta de integração entre as prefeituras nas decisões a serem tomadas para melhorias da região.

\subsection{A Costa da Mata Atlântica}

Costa da Mata Atlântica, segundo o site da Secretaria Estadual de Turismo de São Paulo, é um circuito turístico e também uma região turística. Para o INPI, também é uma marca registrada, sob a responsabilidade do SRC\&VB.

Para o poder público estadual, São Paulo está dividido em quinze macrorregiões e subdividido em trinta e quatro regiões turísticas - levando-se em consideração proximidade e semelhanças de ofertas turísticas. Tal divisão foi criada para viabilizar o incremento de propostas

4 Estâncias são cidades que recebem verba do DADE (Departamento de Apoio ao Desenvolvimento das Estâncias) para melhorarem sua infraestrutura turística. 
e ações voltadas para o desenvolvimento do turismo. A região turística Costa da Mata Atlântica está inserida na macrorregião turística Praias e Mata Atlântica.

Incorporados às regiões turísticas estão os circuitos e roteiros. Na visão da administração, Oliveira e Santos (2006, p. 333) expõem que a organização de circuitos ocorre devido "à necessidade de se obter vantagens competitivas, onde a disponibilidade dos produtos e serviços turísticos devem se complementar"; assim como as características em comum, a história e os atrativos turísticos devem formar um conjunto harmônico, beneficiado pela proximidade entre as cidades componentes do circuito. Para a Secretaria Estadual de Turismo de São Paulo somente as cidades com turismo evidente integram o seleto grupo de circuitos e roteiros paulista. Com isso, organizar cidades com apelo turístico em circuitos e roteiros torna-se um meio sistematizado de promover e divulgar ofertas turísticas em eventos do setor.

O circuito turístico Costa da Mata Atlântica oferece muitas opções de atrativos que podem atender os diversos segmentos do turismo. Segundo levantamento efetuado pelo Sebrae-SP e pelo SRC\&VB, em 2008, são 245 recursos turísticos culturais e naturais a serem ofertados aos visitantes.

Com o objetivo de se quantificar os prestadores de serviços turísticos e melhor caracterizar a região turisticamente (Quadro 2), consultou-se o Cadastur - sistema de cadastro do Ministério do Turismo, que registra os profissionais de turismo, sejam pessoas físicas ou jurídicas. Algumas atividades são de cadastro obrigatório por lei e outras são opcionais.

Quadro 2 - Prestadores de Serviços na Costa da Mata Atlântica

\begin{tabular}{|l|c|c|c|c|c|c|c|c|c|c|}
\hline Prestadores & B & C & G & I & M & P & PG & S & SV & Total \\
\hline Guia de Turismo* & 0 & 10 & 18 & 3 & 3 & 5 & 13 & 110 & 44 & $\mathbf{2 0 6}$ \\
\hline Acampamento Turístico* & 1 & 0 & 0 & 0 & 0 & 0 & 0 & 0 & 0 & 1 \\
\hline Agência de Turismo* & 6 & 5 & 12 & 5 & 3 & 2 & 14 & 116 & 22 & $\mathbf{1 8 5}$ \\
\hline Locadora de Veículos & 0 & 0 & 0 & 0 & 0 & 0 & 1 & 8 & 3 & 12 \\
\hline Meio de Hospedagem* & 4 & 0 & 19 & 5 & 1 & 9 & 5 & 21 & 6 & 70 \\
\hline Organizadora de Eventos* & 1 & 0 & 0 & 0 & 0 & 0 & 1 & 8 & 1 & 11 \\
\hline $\begin{array}{l}\text { Prestador de Infraestrutura de Apoio } \\
\text { para Eventos }\end{array}$ & 0 & 0 & 0 & 0 & 0 & 0 & 0 & 3 & 2 & 5 \\
\hline $\begin{array}{l}\text { Prestador Especializado em Seg- } \\
\text { mentos Turísticos }\end{array}$ & 0 & 0 & 1 & 0 & 0 & 0 & 0 & 1 & 0 & 2 \\
\hline Restaurantes, Cafeterias e Bares & 2 & 0 & 0 & 0 & 0 & 0 & 0 & 0 & 0 & 2 \\
\hline Transportadora Turística* & 3 & 1 & 2 & 2 & 0 & 0 & 0 & 7 & 3 & 18 \\
\hline Total & $\mathbf{1 7}$ & $\mathbf{1 6}$ & $\mathbf{5 2}$ & $\mathbf{1 5}$ & $\mathbf{7}$ & $\mathbf{1 6}$ & $\mathbf{3 4}$ & $\mathbf{2 7 4}$ & $\mathbf{8 1}$ & \\
\hline
\end{tabular}

Legenda: $\mathrm{B}=$ Bertioga, $\mathrm{C}=$ Cubatão, $\mathrm{G}=$ Guarujá, $\mathrm{I}=$ Itanhaém, $\mathrm{M}=$ Mongaguá, $\mathrm{P}=$ Peruíbe, $\mathrm{PG}=\mathrm{Praia}$ Grande, $\mathrm{S}=$ Santos, $\mathrm{SV}=$ São Vicente.

Fonte: Elaboração dos autores. 
Tourism in Analysis

Observa-se que, na prática, o número de prestadores é bem maior do que os cadastrados no Cadastur, o que sugere a necessidade de uma maior atuação dos órgãos competentes, visando a legalização dos prestadores.

O conjunto das nove cidades oferece atrativos naturais, históricos, opções gastronômicas, artesanato, aventuras esportivas, espaços para eventos de grande porte -como shows -, além de variadas opções de hospedagem - incluindo hotéis de reconhecidas cadeias mundiais e pousadas. A cidade de Bertioga é conhecida por sua paisagem natural, já que $85 \%$ de seu território é preservado, tendo 36 quilômetros de praias limpas. A cidade também oferece pontos para pesca e atividades radicais, como: surfe e rafting. Como aspecto histórico, possui o primeiro forte construído no Brasil, em 1532, o forte de São João.

A cidade de Cubatão abriga o polo industrial químico e petroquímico. Além disso, é sede do Parque Estadual da Serra do Mar, que oferece trilhas, cachoeiras e passeio pelo rio Cubatão. A cidade de Guarujá oferece diversas praias e locais para prática de esportes radicais e também passeios por fortes e fortalezas. A cidade abriga o maior aquário da América do Sul em exposição de organismos aquáticos. Além disso, possui a rede hoteleira mais luxuosa da região, capaz de atender ao público mais exigente.

O município de Itanhaém oferece praias, cachoeiras, ilhas para prática de mergulho e também um roteiro religioso com seis locais que remetem à vida do Padre Anchieta.

A cidade de Mongaguá possui praias com quiosques, feira de artesanato e uma das maiores plataformas de pesca do mundo, com 400m que adentram ao mar. Outro grande atrativo é o Poço das Antas, local com piscinas naturais, trilhas, cachoeiras e espaço para alimentação em meio à Mata Atlântica.

O município de Peruíbe abriga a Estação Ecológica de Jureia-Itatins, que integra a Reserva da Biosfera da Mata Atlântica, considerada pela Unesco como Patrimônio Natural da Humanidade. O local possui espécies raras da fauna e flora, além de oferecer cachoeiras, rios e trilhas, que podem ser conhecidas por meio de visitas monitoradas. A cidade também possui monumentos históricos, praias e a lama negra - material natural, que tem propriedades medicinais e estéticas.

A cidade de Praia Grande é composta por 22,5 quilômetros de praias urbanizadas, com ciclovia, jardins, monumentos culturais e serviços para os turistas. 
Tourism in Analysis

A cidade de Santos é uma estância multifacetada que atende todos os tipos de visitantes. Para os que vêm a negócios, a cidade possui infraestrutura hoteleira, centro de convenções e opções de transporte; para os que procuram lazer, a cidade oferece parques, praias com infraestrutura e passeios diversos. Para os que procuram natureza e tranquilidade, a cidade possui uma área continental com cachoeiras, riachos, atividades rurais e comunidade caiçara, além da Lage de Santos, local de preservação ambiental muito procurado para prática de mergulho. Santos é a cidade do maior porto da América Latina, ponto de passagem das rotas de cruzeiros marítimos. A cidade também possui o maior jardim de praia em extensão do mundo, segundo o Guinness Book.

São Vicente foi a primeira vila fundada pelos portugueses na América, o que lhe rendeu a alcunha de "Cellula-Mater da Nacionalidade". A cidade oferta praias, rios, nos quais há prática de esportes náuticos, museus, teleférico, local para prática de voo livre e infraestrutura completa de serviços. De acordo com o Guinness Book, o município também é conhecido pelo maior espetáculo teatral em areia de praia do mundo - a encenação da fundação da Vila de São Vicente. Graças aos diversos atrativos turísticos, as cidades da RMBS demonstram aspirações para ações de turismo. Para organizar e direcionar essas, foi criado pelo governo estadual o circuito Costa da Mata Atlântica, marca, registrada sob responsabilidade do SRC\&VB, que visa promover a região em eventos e nas lembranças dos turistas.

\section{Processo de criação da marca Costa da Mata Atlântica}

No ano de 2002 foi entregue pela Associação Educacional do Litoral Santista - hoje Centro Universitário Monte Serrat - o Plano Diretor de Turismo da Baixada Santista (PDTur/BS), solicitado pela Agência Metropolitana da Baixada Santista (AGEM), que sugeria a criação de uma marca cuja denominação seria Costa Matriz.

Segundo (AFFONSO; LANZA, 2002, p. 132) “o termo Costa, que confere unidade à região, é internacionalmente reconhecido como indicador de litoral, com conotações de atratividade turística". O termo Matriz é, ao contrário, inexistente como indicador de regiões, criando por si só um grande diferencial. 
Tourism in Analysis

Porém, em abril de 2002 foi criado, na Região Metropolitana da Baixada Santista, o Santos e Região Convention \& Visitors Bureau, entidade associativa, sem fins lucrativos, formada pela união pública e privada, que tem como missão a promoção do turismo de lazer e negócios da região.

Conforme os registros de atas, verificou-se que, depois de inúmeras reuniões com os secretários de turismo, empresários, prefeitos, representantes das entidades de classe da região, a entidade precisava atender a necessidade de criação de uma identidade visual e um nome que representasse a região, de Bertioga à Peruíbe, de forma única.

No mesmo ano, o SRC\&VB, juntamente com a empresa Ego Comunicação Estratégica, criou a marca Costa da Mata Atlântica, um selo turístico que tem como objetivo levar a RMBS a possuir a mesma temática turística de base regional em território nacional e internacional. De modo a atender a proposta feita no PDTur/BS, que diz que "a proposta de marcar a Região através de um conceito diferencial forte tem a intenção de direcionar a preferência não apenas como alternativa, mas em função de um forte atrativo, que leve a essa preferência diretamente por associação com aquele conceito" (AFFONSO; LANZA, 2002, p. 132). Assim, em 2003 foram apresentadas cinco propostas de logomarca com o conceito de representação da natureza aos nove secretários de turismo da localidade para votação. A imagem eleita é apresentada na Figura 1.

Figura 1 - Marca Criada em 2003

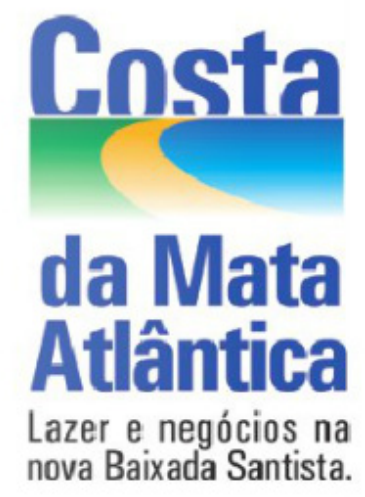

Fonte: Catálogo do Circuito Turístico da Costa da Mata Atlântica (2003) 
Tourism in Analysis

A marca Costa da Mata Atlântica teve, em 2014, seu slogan alterado, com a retirada da frase "Lazer e negócios na nova Baixada Santista" sendo substituída para "Única para você" - fator que ocorreu devido às novas estratégias de marketing nas campanhas promocionais do destino.

Figura 2 - Marca Atual

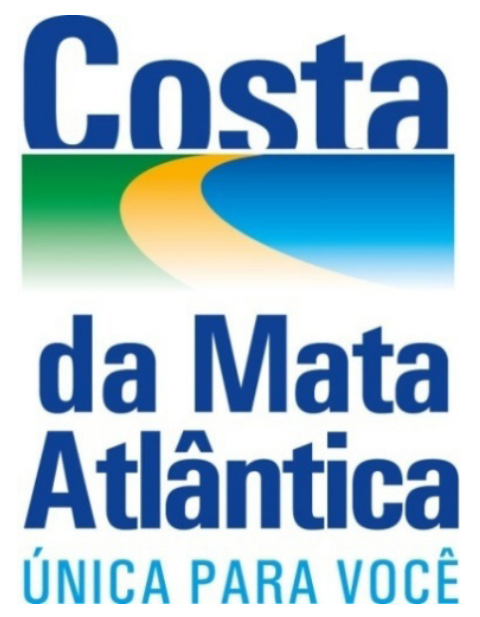

Fonte: Acervo Santos e Região Convention \& Visitors Bureau (2014)

A marca Costa da Mata Atlântica coloca a Característica Geográfica em primeiro plano, enfatizando a fauna e a flora. Utiliza, ainda, essa referência como Posição Destacada, ao ressaltar a concentração da diversidade e, em alguns casos, da exclusividade de certos exemplares. Em segundo plano, ou complementarmente, inclui a história e o esporte, pretendendo abranger desde o turismo tradicional (lazer) ao de negócios. (VAZ, 2004, p. 6)

A marca é de natureza mista e de serviços - por unir design e letras -, e faz alusão ao bioma da Mata Atlântica, o qual é predominante em todas as cidades da região. Porém, ela também retrata, por meio de suas cores, as seguintes ideias: verde: costa, mata e ecologia; amarelo: praia, litoral e areia; azul: mar, oceano e água.

Sua aplicabilidade, segundo o INPI, deve ser em organização de congressos, convenções e exposições, mostras, feiras, eventos, atividades educacionais, cursos, treinamento e aperfeiçoamento de recursos humanos, atividades culturais, esportivas e recreativas.

Por ser de domínio público, qualquer empresa pode utilizar a marca em seus materiais promocionais, pois é uma maneira de divulgar a região em território nacional e internacional. 
Tourism in Analysis

\section{Avaliação da marca por medida direta - notoriedade}

Uma marca notória é aquela que é reconhecida, lembrada e memorizada de tal forma que ela se distingue das demais; é a marca cujo grau de lembrança e perceptibilidade é grande junto a seu público-alvo.

Um dos meios de avaliação de uma marca é por meio de sua notoriedade, ou seja, é a maneira que o consumidor de determinado produto ou serviço consegue se relacionar a ela. Segundo Louro (2000, p. 31):

A notoriedade de uma marca reflete o conhecimento e a sua predominância na mente do consumidor. Essa dimensão pode ser medida fundamentalmente em dois níveis: notoriedade espontânea ou "memorização" (recall) e notoriedade assistida ou "reconhecimento" (recognition).

As formas que a notoriedade se apresenta são: Recall (memorização) - que se refere à predisposição de uma marca a ser memorizada quando um consumidor pensa sobre uma categoria específica de um produto; e Recongnition (reconhecimento) - que se define pela situação em que o consumidor é apto de distinguir uma marca da outra de um produto ou serviço do mesmo ramo de atuação (LOURO, 2000).

Mas, para construir a notoriedade, uma marca deve ser exposta de formas repetidas, por meio de mensagens promocionais do produto ou serviço aos quais ela se refere, e também por via dos critérios, como mencionado no processo de criação de uma marca.

Dessa forma, ela pode se tornar top of mind - que nada mais é do que a primeira marca a ser lembrada -, fazer parte das marcas mais importantes de forma espontânea, ou então ser mais uma entre tantas que se sobrepõem por devido reconhecimento ou não.

A contribuição do estudo da notoriedade de uma marca é fundamentada na intenção de criar meios para tomadas de decisão, tendo em vista o conhecimento não somente da marca em si, mas também da concorrência ao setor de atividade que ela está envolvida.

Dados como espontaneidade de reconhecimento, identificação dos atributos e relação da imagem ao produto e ou serviço, fazem a marca ter sua importância, o que pode garantir que a capacidade de percepção derivada do esforço de promoção em mídias dê o resultado esperado e torne a marca familiar ao consumidor. 
Tourism in Analysis

Tais aspectos também se referem ao âmbito turístico, pois, ao possuir uma marca, o destino passa a ter uma identidade para o turista, e consequentemente para o residente, já que o local se torna diferenciado perante os demais.

Segundo Pimentel, Pinho e Vieira (2006, p. 290) "ter um destino turístico com uma marca formada é essencial para o reconhecimento e a lembrança do visitante. Pode representar associação de atrações, de pessoas e seu estilo de vida ou um atrativo em especial”. Portanto, a memorização de um destino não está ligada apenas aos seus atrativos, também estará ligada à marca de forma notória, assim se torna simples a criação de estratégias de marketing turístico para o destino ao qual essa identidade é pertencente. Mas para conseguir desenvolver tais estratégias de marketing

é, pois, importante compreender como a marca é vista pelos visitantes e potenciais visitantes para desenvolver, adaptar ou fazer evoluir o posicionamento estratégico da marca. Isso possibilita conhecer quais as direções a não tomar para não destruir a imagem que se criou e, conseguir inovar, surpreendendo o consumidor. (PIMENTEL; PINHO; VIEIRA, 2006, p. 294)

Kastenholz (2002) afirma que as marcas turísticas são criadas com a intenção de transmitir e representar a hospitalidade, o clima, a natureza, os pontos turísticos, entre outras características que consiga encantar potenciais turistas.

\section{Metodologia}

Este estudo se caracteriza como exploratório e descritivo. A investigação exploratória procura descobrir novas ideias, perspectivas e aspectos da realidade. Já a descritiva, conforme Gil (1999), tem como objetivo primordial a descrição das características de determinada população ou fenômeno ou, então, o estabelecimento de relações entre variáveis de forma objetiva. A composição da amostra é um dos pontos a ser destacado devido à especificidade e a legitimidade dos resultados (LAKATOS, MARCONI; 1992). Portanto, para este estudo a amostragem é não probabilística e foi selecionada por conveniência na qual o pesquisador elege membros da população mais acessíveis (AAKER; KUMAR; DAY, 2001). Assim, a pesquisa foi realizada com o objetivo de identificar e analisar o número de pessoas que já conhecem ou ouviram falar da região Costa da Mata Atlântica e sua marca. O instrumento utilizado para a coleta das informações foi um questionário estruturado com perguntas abertas e fechadas. 
Tourism in Analysis

Aaker, Kumar e Day (2001) apresentam que a população-alvo é definida como um conjunto de sujeitos que possui algumas características comuns em relação ao problema de pesquisa. Assim, para a coleta de dados foram considerados sujeitos, homens e mulheres, com idade acima de dezoitos anos, residentes em cidades não pertencentes à RMBS.

A aplicação do questionário foi realizada na alta temporada, por apresentar um aumento significativo da demanda turística, e em dois locais diferentes, com o objetivo de diversificar a amostra. A primeira aplicação foi em 10 de outubro de 2015, no Auto Posto Biritiba Ussu, localizado na rodovia Dom Paulo Rolim Loureiro (Mogi-Bertioga), número 20, que fica em Mogi das Cruzes, em São Paulo; e a segunda, durante o período de 8 à 16 de novembro de 2015, foi realizada no Concais S.A - Terminal Marítimo de Passageiros Giusfredo Santini -, situado na avenida Cândido Gafre, no bairro Docas, em Santos, no estado de São Paulo. No total foram aplicados 130 questionários.

Após a coleta de dados, os pesquisadores direcionaram sua atenção à análise e interpretação das informações coletadas, com o objetivo de reunir as observações de maneira coerente e organizada, verificando se a marca Costa da Mata Atlântica teria a notoriedade maior entre os visitantes do que termo "Baixada Santista".

Foi realizada, primeiramente, uma análise dos dados, por meio de tabulação no programa Excel, que permitiu o tratamento informatizado dos dados e o cruzamento das informações, possibilitando uma observação mais precisa da realidade estudada. Na sequência, foi realizada uma análise descritiva dos dados.

\section{Apresentação dos resultados}

Os dados resultantes dos 130 questionários aplicados apresentaram informações interessantes e que contribuirão diretamente com o desenvolvimento turístico da região, especificamente com as estratégias de marketing do destino. Devido a extensão de dados da pesquisa, para este artigo optou-se em apresentar as informações mais relevantes de acordo com o problema e os objetivos apresentados.

No que refere aos entrevistados, quanto à cidade de residência, verificou-se que apenas $13 \%$ dos turistas eram moradores de outros estados brasileiros, todos os outros $87 \%$ eram 
Tourism in Analysis

residentes do estado de São Paulo, sendo a maioria da capital paulista (39\%). Empiricamente, o dado que se refere à capital paulista já era conhecido, porém, com esta amostragem ficou evidenciado que a demanda turística maior da localidade é proveniente da capital. Dado que pode influenciar na direção das estratégias de marketing do local.

Quanto ao destino, mais da metade dos entrevistados se dirigiam a uma das nove cidades que compõem a Costa da Mata Atlântica (51\%). Tinham como destino outras cidades do litoral paulista $42 \%$ - como, por exemplo, as cidades do litoral norte do estado e a região de Cananéia -, e apenas 7\% não estavam viajando para o litoral paulista - trajeto de passagem para o estado do Rio de Janeiro, Paraná e outras localidades. Essa informação permitiu identificar e entender que apesar de muitos viajantes (49\%) não terem como destino final cidades da Costa da Mata Atlântica eles passam pela localidade e utilizam sua infraestrutura (postos de combustíveis, restaurantes, lanchonetes, lojas de souvenirs, farmácias e outros serviços) - dado relevante, que contribui diretamente com as políticas públicas e com o setor privado da região, que poderá, a partir dessas informações, direcionar suas ações.

Já no que se refere especificamente aos questionamentos sobre a marca Costa da Mata Atlântica e ao emprego popular do termo "Baixada Santista", temos:

Quadro 3 - Perguntas e respostas "fechadas" dos entrevistados

\begin{tabular}{|c|c|c|}
\hline Perguntas & \multicolumn{2}{|c|}{ Respostas } \\
\hline Você já ouviu falar sobre a Região Metropolitana da & Sim -122 & Não -8 \\
Baixada Santista? & $94 \%$ & $6 \%$ \\
\hline \multirow{2}{*}{ Você já ouviu falar sobre a Costa da Mata Atlântica? } & Sim -64 & Não -66 \\
\hline Você já viu essa imagem? Apresentação do logo da & Sim - 49 & Não $-81 \%$ \\
Costa da Mata Atlântica. & $38 \%$ & $62 \%$ \\
\hline
\end{tabular}

Fonte: Autores

Observa-se que praticamente todos os entrevistados (94\%) têm conhecimento da RMBS, evidenciando que se trata de um termo popularizado e reconhecido pelos visitantes entrevistados. Ao que se refere à nomenclatura Costa da Mata Atlântica apenas 49\% dos entrevistados declaram que já ouviram falar sobre a marca. Quando os pesquisadores apresentaram visualmente a marca Costa da Mata Atlântica aos entrevistados, menos da metade declarou que se lembrava de ter visto a logomarca - dados que correspondem a $38 \%$. 
A partir deste resultado, torna-se evidente que a marca Costa da Mata Atlântica atualmente possui baixa notoriedade, ou seja, na maioria das vezes não é lembrada e nem destacada na memória dos turistas, segundo a avaliação por notoriedade proposta por Louro (2000).

Sendo a notoriedade um dos meios de avaliação de uma marca, conclui-se que os visitantes ainda não se relacionam com a marca em questão. Os autores Molina, Frías-Jamilena e CastañedaGarcía (2012) corroboram que as atitudes e a percepção sobre a marca dos destinos turísticos são importantes preditores da escolha de um destino, das intenções de regresso do visitante, como também da lealdade a um destino. Portanto, os resultados relacionados à notoriedade da marca destino Costa da Mata Atlântica apontam para uma necessidade emergente de novas práticas e ações de marketing para a região, visando relacionar os aspectos do destino com a marca constituída, a fim de se obter resultados efetivos ao que se refere à aplicação da marca e sua finalidade. Como sugestão para um ponto de partida, pode-se inicialmente trabalhar as percepções sobre a marca Costa da Mata Atlântica em atividades internas do próprio destino, na tentativa de se estabelecer um reconhecimento de comunicação e colaboração entre todos os interessados por meio da marca, conforme apresentado por Choo, Sun-Young e Petrick (2011).

Quadro 4 - Qual/quais cidade(s) você acredita que faz/fazem parte dessa região?

\begin{tabular}{|c|c|c|}
\hline $\begin{array}{c}\text { Pergunta: Qual/quais cidade(s) você acredita que faz/fazem parte des } \\
\text { região? }\end{array}$ & & $\begin{array}{l}\text { Resultado } \\
\text { em } \%\end{array}$ \\
\hline $\begin{array}{l}\text { Número de entrevistados que acertaram exatamente quais cidades com- } \\
\text { põem a região }\end{array}$ & 1 & $1 \%$ \\
\hline $\begin{array}{l}\text { Número de entrevistados que citaram corretamente pelo menos uma } \\
\text { cidade que compõe a região }\end{array}$ & 38 & $59 \%$ \\
\hline
\end{tabular}

Fonte: Autores.

Observa-se que quase metade dos entrevistados declarou que já ouviu falar sobre a Costa da Mata Atlântica, mas somente um dos entrevistados sabe exatamente quais cidades a compõe. Um pouco mais da metade (59\%) dos que declararam que já ouviram falar sobre a região, citou pelo menos uma cidade componente; e 25\% disseram que a região era composta pelo litoral paulista ou litoral nacional, associando a palavra "Costa" ao litoral em sua totalidade. Também foi verificada, por meio dos comentários de diversos entrevistados, a confusão causada por parte da nomenclatura utilizada para a região. Os entrevistados destacavam "Mata Atlântica" e remetiam ao bioma brasileiro. Todas essas observações evidenciam 
Tourism in Analysis

que, na mente dos turistas, a marca Costa da Mata Atlântica não remete à região de estudo, mas sim para algo abrangente, uma extensão territorial estadual ou até mesmo nacional. Ou seja, a marca ainda não cumpre sua função identificadora. O ideal seria que o turista, ao ver a marca, lembrasse das cidades da região, conforme exposto pelos autores Pérez-Nebra e Torres (2002), que enfatizam o quanto é importante desenvolver uma imagem baseada na identidade do destino, a qual deve ser utilizada adequadamente para transformá-lo em um potencial turístico.

Conclui-se, portanto, que a marca Costa da Mata Atlântica ainda não obteve o seu grau de reconhecimento notório pelos visitantes da região e que deve ser incorporada em outras ações estratégicas de marketing, em acordo com o proposto por Klijin, Eshuis e Braun (2012), que relatam que o marketing de destino deve ter como objetivo construir significados positivos de lugares, comunicando uma seleção física, emocional e atributos do lugar.

\section{Considerações}

O presente trabalho atingiu o objetivo principal e respondeu ao problema de pesquisa inicialmente proposto: a marca Costa da Mata Atlântica tem uma notoriedade maior entre os turistas do que termo "Baixada Santista" usualmente empregado?

Portanto, o estudo revelou que o termo "Baixada Santista" é reconhecido, praticamente, por todos os entrevistados, enquanto nem metade deles conhecem o termo e a marca Costa da Mata Atlântica. Conforme a exposição de Pimentel, Pinho e Vieira (2006) é importante compreender como a marca é vista pelos visitantes e potenciais visitantes, dessa forma, é possível desenvolver campanhas, adaptar o posicionamento estratégico da marca e direcioná-la para ações mais efetivas referentes ao marketing de destino.

Assim, os resultados obtidos ao final do trabalho implicam diretamente na prática de atuação dos gestores da região turística, pois os questionamentos realizados, no sentido de identificar a percepção do visitante ao selo turístico Costa da Mata Atlântica, irão favorecer as estratégias de marketing e o desenvolvimento turístico regional, possibilitando ao poder público, ao trade e a todos os atores envolvidos com o turismo, um redirecionamento primordial para o desenvolvimento turístico na localidade. 
Tourism in Analysis

Evidencia-se a necessidade de formas mais efetivas de marketing para promover e consolidar a marca Costa da Mata Atlântica. Não só o símbolo em si, mas principalmente a relação com a região representada por essa marca.

Ressalta-se que este foi o primeiro estudo realizado sobre a marca Costa da Mata Atlântica e que, embora tenha-se alcançado satisfatoriamente os objetivos traçados, ficaram no estudo algumas limitações. A primeira refere-se ao escopo do modelo da pesquisa, que se resumiu a poucas questões, restringindo o entendimento de outras possíveis inter-relações. Outro ponto de fragilidade foi a amostra obtida que, apesar de ter tornado o estudo consistente e estar consonante com pesquisas na área, possui uma construção amostral limitada. Assim, é importante que os próximos estudos utilizem amostras maiores, sendo possível realizar o mesmo tipo de questionamento também aos residentes da região turística Costa da Mata Atlântica.

\section{Referências}

AAKER, D. A. Marcas: brand equity, gerenciando o valor da marca. São Paulo: Negócio, 1998.

AAKER, D. A.; KUMAR, V.; DAY, G. S. Pesquisa de Marketing. São Paulo: Atlas, 2001.

AFFONSO, A. N.; LANZA, M. O. P. Plano Diretor de Turismo da Baixada Santista-PDTUR/BS: Prognóstico 2002. Disponível em: <http://bit.ly/2gsEyUG>. Acesso em: 26 nov. 2016.

AGÊNCIA METROPOLITANA DA BAIXADA SANTISTA. Perfil Municipal. Disponível em: $<$ http://bit.ly/2fzgISN $>$. Acesso em: 26 nov. 2016.

ATLAS DO DESENVOLVIMENTO HUMANO NO BRASIL. Atlas Brasil - Santos, SP. 2013. Disponível em: <http://bit.ly/2fzc2MB > . Acesso em: 26 nov. 2016.

BANKS, S. The relationship between preference and purchase of brands. The Journal of Marketing, v. 15 , n. 2, p. 145-157, 1950.

BLAIN, C.; LEVY, S. E.; RITCHIE, J. R. B. Destination branding: insights and practices from destination management organizations. Journal of Travel Research, v. 43, n. 4, p. 328-338, 2005.

BRASIL. Casa Civil. Lei da Propriedade Industrial no 9279, de 14 de maio de 1996. Regula direitos e obrigações relativos à propriedade industrial. Diário Oficial da União, Brasília, DF, 15 mai. 1996. Seção 1, p. 8353. 
Tourism in Analysis

Ministério do Turismo. Cadastur. 2010. Disponível em: $<$ http://bit.ly/2fzntUG $>$. Acesso em: 26 nov. 2016.

CENTRO DAS INDÚSTRIAS DO ESTADO DE SÃO PAULO. História da regional do CIESP em Cubatão. 2015. Disponível em: <http://bit.ly/2gsVFpd>. Acesso em: 26 nov. 2016.

CHOO, H.; SUN-YOUNG, P.; PETRICK, J. F. The influence of the resident's identification with a tourism destination brand on their behavior. Journal of Hospitality Marketing \& Management, v. 20, n. 2, p. 198-216, 2011.

GARDNER, B. B.; LEVY, S. J. The product and the brand. Harvard Business Review, p. 33-39, mar.-abr. 1955.

GIL, A. C. Métodos e técnicas de pesquisa social. 5. ed. São Paulo: Atlas, 1999.

INSTITUTO BRASILEIRO DE GEOGRAFIA E ESTATÍSTICA. IGBE. Disponível em: < $<\mathrm{http}: / / \mathrm{bit}$. ly/1Bf6v1w>. Acesso em: 26 abr. 2016.

KAPFERER, J.-N. Strategic brand management: creating and sustaining brand equity long term. London: Kogan Page, 2000.

The new strategic brand management: creating and sustaining brand equity long term. London: Kogan Page, 2004.

KASTENHOLZ, E. The role and marketing implications of destination images on tourism behavior: the case of northern Portugal. 2002. 392 f. Tese (Doutorado em Turismo) - Departamento de Economia, Gestão e Engenharia Industrial, Universidade de Aveiro, Aveiro, 2002.

KELLER, K. L. Strategic brand management: building, measuring, and managing brand equity. Upper Saddle River, NJ: Prentice Hall, 2003.

KLIJN, E.-H.; ESHUIS, J.; BRAUN, E. The influence of stakeholder involvement on the effectiveness of place branding. Public Management Review, v. 14, n. 4, p. 499-519, 2012.

KOTLER, P. Marketing management: analysis, planning, implementation, and control. 7. Ed. New Jersey: Prentice Hall 1991.

KOTLER, P.; GERTNER, D. Country as brand, product, and beyond: a place marketing and brand management perspective. The Journal of Brand Management, v. 9, n. 4-5, p. 249-261, 2002.

KOTLER, P.; KELLER, K. L. Administração de marketing. 10. ed. São Paulo: Prentice Hall, 2000. 
Tourism in Analysis

LAKATOS, E. M.; MARCONI, M. A. Metodologia do trabalho científico: procedimentos básicos, pesquisa bibliográfica, projeto e relatório, publicações e trabalhos científicos. São Paulo: Atlas, 1992.

LINDON, D. et al. Mercator XXI - Teoria e prática do marketing. 10. ed. Lisboa: Dom Quixote, 2004.

LOURO, M. J. S. Modelos de avaliação de marca. RAE - Revista de Administração de Empresas, v. 40, n. 2, p. 26-37, 2000.

MARTINS, J. R. Grandes marcas grandes negócios: como as pequenas e médias empresas devem criar e gerenciar uma marca vendedora. 2. ed. São Paulo: Global Brands, 2005.

MOILANEN, T.; RAINISTO, S. How to brand nations, cities and destinations: a planning book for place branding. New York: Palgrave Macmillan, 2009.

MOLINA, M. Á. R., FRÍAS-JAMILENA, D.-M.; CASTAÑEDA-GARCÍA, J. A. The moderating role of past experience in the formation of a tourist destination's image and in tourists' behavioural intentions. Current Issues in Tourism, v. 16, n. 2, p. 107-127, 2012.

OLIVEIRA, J. M. S. R.; SANTOS, A. C. O turismo como alternativa para o desenvolvimento da competitividade: uma análise da "rota dos tropeiros" no oeste de Minas Gerais. Revista Facef Pesquisa, v. 9, n. 3, p. 332-342, 2006.

PÉREZ-NEBRA, A. R.; TORRES, C. V. Imagem do Brasil como país de destino turístico: uma pesquisa da psicologia do consumidor. Turismo: Visão e Ação, v. 4, n. 10, p. 101-114, 2002.

PIKE, S. Destination brand positions of a competitive set of near-home destinations. Tourism Management, v. 30, n. 6, p. 857-866, 2009.

PIMENTEL, E.; PINHO, T.; VIEIRA, A. Imagem da marca de um destino. Turismo: Visão e Ação, v. 8, n. 2, p. 283-298, 2006.

PRITCHARD, A.; MORGAN, N. Mood marketing - the new destination branding strategy: a case of Wales' the brand. Journal of Vacation Marketing, v. 4, n. 3, p. 215-229, 1998.

SANTOS E REGIÃO CONVENTION \& VISITORS BUREAU. Disponível em: < http://bit.ly/1gR9BiH>. Acesso em: 26 nov. 2016.

SÃO PAULO (Cidade). Estâncias turísticas. Disponível em: $<$ http://bit.ly/2gxinKD $>$. Acesso em: 26 nov. 2016. 


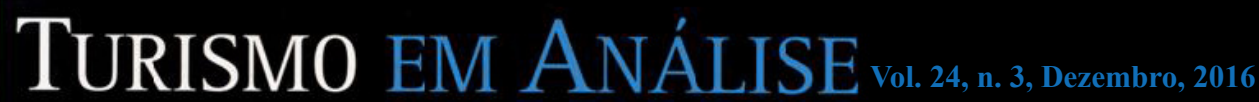

Tourism in Analysis

Lei de criação da Região Metropolitana da Baixada Santista. Lei Complementar, no 815, de 30 de julho de 1996. Diário Oficial do Estadual de São Paulo, Poder Executivo, São Paulo, SP, 31 jul.1996. Seção 1, p. 1.

SERVIÇO BRASILEIRO DE APOIO ÀS MICRO E PEQUENAS EMPRESAS. Catálogo circuito turístico Costa da Mata Atlântica. 2003. Disponível em: <http://bit.ly/2fzmvrf $>$. Acesso em: 26 nov. 2016.

SIMÕES, C.; DIBB, S. Rethinking the brand concept: new brand orientation. Corporate Communications, v. 6, n. 4, p. 217-224, 2001.

VAZ, G. N. Costa da Mata Atlântica: implicações culturais e mercadológicas da marca turística da Baixada Santista. Patrimônio: Lazer e Turismo, n. 2, p. 1-12, 2004.

Recebido em: 13/04/2016 (1 ${ }^{\text {a }}$ versão) 11/08/2016 (2 ${ }^{\mathrm{a}}$ versão) $20 / 09 / 2016$ (3 ${ }^{\mathrm{a}}$ versão)

Aprovado em: 06/10/2016 